
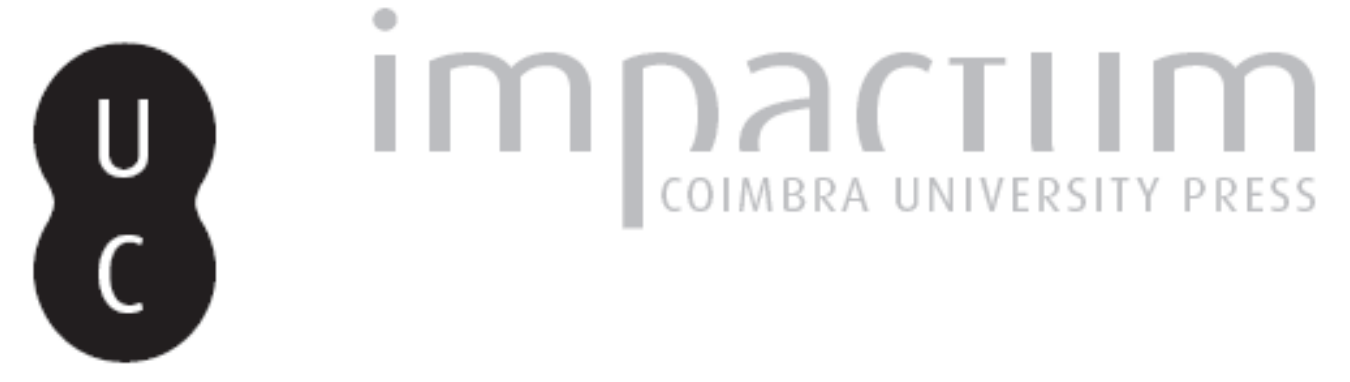

O retorno ao mundo da vida: Merleau-Ponty, Leitor de Husserl

Autor(es): $\quad$ Silva, Claudinei Aparecido de Freitas da

$\begin{array}{ll}\text { Publicado por: } & \text { Faculdade de Letras da Universidade de Coimbra, Instituto de Estudos } \\ & \text { Filosóficos }\end{array}$

URL

persistente:

URI:http://hdl.handle.net/10316.2/29461

DOI:

DOI:http://dx.doi.org/10.14195/0872-0851_41_1

Accessed : $\quad$ 26-Apr-2023 12:37:18

A navegação consulta e descarregamento dos títulos inseridos nas Bibliotecas Digitais UC Digitalis, UC Pombalina e UC Impactum, pressupõem a aceitação plena e sem reservas dos Termos e Condições de Uso destas Bibliotecas Digitais, disponíveis em https://digitalis.uc.pt/pt-pt/termos.

Conforme exposto nos referidos Termos e Condições de Uso, o descarregamento de títulos de acesso restrito requer uma licença válida de autorização devendo o utilizador aceder ao(s) documento(s) a partir de um endereço de IP da instituição detentora da supramencionada licença.

Ao utilizador é apenas permitido o descarregamento para uso pessoal, pelo que o emprego do(s) título(s) descarregado(s) para outro fim, designadamente comercial, carece de autorização do respetivo autor ou editor da obra.

Na medida em que todas as obras da UC Digitalis se encontram protegidas pelo Código do Direito de Autor e Direitos Conexos e demais legislação aplicável, toda a cópia, parcial ou total, deste documento, nos casos em que é legalmente admitida, deverá conter ou fazer-se acompanhar por este aviso.

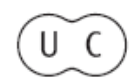




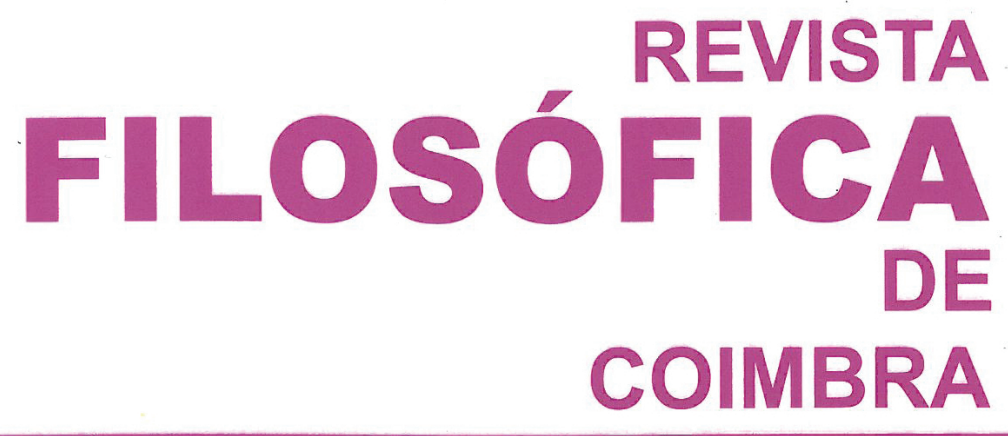

vol. 21 - número 41 - março 2012

vol. 21 - número 41 - março 2012

Fundação Eng. António de Almeida

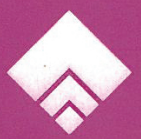




\title{
O RETORNO AO MUNDO DA VIDA: MERLEAU-PONTY, LEITOR DE HUSSERL
}

\author{
CLAUDINEI APARECIDO DE FREITAS DA SILVA*
}

Resumo: O presente artigo visa reconfigurar, em linhas gerais, o estatuto da problemática do retorno ao "mundo da vida" perspectivado à luz da releitura merleau-pontyana de Husserl. Para tanto, esse tema será circunscrito no contexto emergente da tradição fenomenológica, onde Merleau-Ponty situa a importância da figura de Heidegger revisitando criticamente, ao mesmo tempo, o alcance e os limites da exigência metódica da redução. Trata-se de avaliar em que medida o próprio Merleau-Ponty retoma, programaticamente, esse tema tão caro à fenomenologia, visando aprofundá-lo sob a perspectiva de uma ontologia da carne perpassada por uma nova concepção de natureza em curso.

Palavras-chave: Husserl. Redução. Mundo da vida. Merleau-Ponty, Natureza, Carne.

Abstract: This article aims at assessing anew, in general terms however, the status of the "life world" problematic viewed in the light of Merleau-Ponty's rereading of Husserl. This will be addressed in the frame of the emerging phenomenological tradition, inwhere Merleau-Ponty situates Heidegger's importance, and critically the scope and limits of the methodical requirements of reduction. This it will be done by evaluating the extent to which Merleau-Ponty himself revisits, programmatically, a theme so important to phenomenology by deepening it under the perspective of an ontology of the flesh pervaded by a new conception of nature

Keywords: Husserl. Reduction. Lebenswelt. Merleau-Ponty. Nature. Flesh.

* Bolsista da CAPES - Proc. no 0716-11-1”, referente a Estágio Pós-Doutoral na Université Paris 1 - Panthéon-Sorbonne entre dez/2011 a nov/2012. Professor dos Cursos de Graduação e de Pós-Graduação (Mestrado) em Filosofia da UNIOESTE. E-mail: cafsilva@uol.com.br Conferência ministrada na $1^{a}$ Jornada de Metafísica \& Conhecimento "A Fenomenologia Husserliana e seu Legado", no período de 13 a 14 de maio de 2008, na UNIOESTE - Campus Toledo. 
Em 1945, Merleau-Ponty prefacia, na abertura da Phénoménologie de la Perception, um sumário balanço da fenomenologia inaugurada por Husserl:

O que é a fenomenologia? Pode parecer estranho que ainda se precise colocar essa questão meio século após os primeiros trabalhos de Husserl. Ela está longe, todavia, de estar resolvida. A fenomenologia é o estudo das essências [...], mas é também uma filosofia que repõe as essências na existência, e não pensa que se possa compreender o homem e o mundo de outra maneira senão a partir de sua 'facticidade'. É uma filosofia transcendental que coloca em suspenso, para compreendê-las, as afirmações da atitude natural. Por outro lado, é também uma filosofia para a qual o mundo já está sempre 'ali', antes da reflexão, como uma presença inalienável, e cujo esforço todo consiste em reencontrar este contato ingênuo com o mundo, para dar-lhe enfim um estatuto filosófico (Merleau-Ponty, 1945, p. i).

\section{I}

Ao fazer tal balanço, o pensador francês perspectiva o sentido e o alcance da fenomenologia não só desde a produção inaugural de Husserl, mas, sobretudo, o seu raio de abrangência na posteridade filosófica. Assim, se é verdade que a fenomenologia reivindica um método próprio de trabalho, instituindo-se, pois, no sentido de uma práxis ou de um movimento antes mesmo de adquirir maior consciência filosófica, é porque também os seus temas devem ser circunscritos à maneira como se ligaram mais espontaneamente na vida. Eis a razão pela qual a fenomenologia permanece, ainda, como um projeto amplamente aberto, sempre iniciante e em estado de promessa. O que Merleau-Ponty também traz à baila nesse registro é um importante horizonte temático por meio do qual a fenomenologia ganha impulso. Ou seja, embora ela se defina em termos de um novo empre-

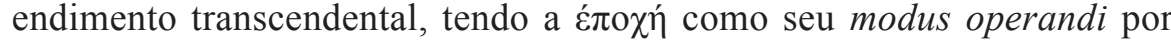
excelência, ela também se perfila como um ensaio hermenêutico acerca da facticidade. É sob esse contexto que "todo o Sein und Zeit nasceu de uma indicação de Husserl tornando-se, em suma, uma explicitação apenas do 'natürlichen Weltbegriff' [conceito natural do mundo] ou da 'Lebenswelt' [mundo da vida] que Husserl, no final de sua vida, apresentava como o tema primeiro da fenomenologia" (Merleau-Ponty, 1945, p. i). Ora, se é verdade que Heidegger leva a sério essa indicação, isso não significa que ele corroborará as teses mais canonicamente ortodoxas de seu mestre. Pois era sintomaticamente a compreensão em torno do estatuto dessa questão primeira que também viria marcar, em definitivo, a ruptura entre ambos, na medida em que Heidegger irá propor outro programa transcendental nos termos de uma analítica existencial, alterando, significativamente, a agenda fenomenológica da análise intencional. Trata-se, na verdade, de interrogar o sentido último de uma nova ordem de estrutura resistente a 
toda e qualquer operação constituinte, ou seja, o cumprimento da exigência de uma explicitação ontológica fundamental do In-der-Welt-Sein [ser-no-mundo]. É o estatuto mais próprio da mundanidade do mundo como fenômeno inalienável que passa a entrar em questão. É esse tema que se converterá numa indicação recorrente enquanto índice de um questionamento permanente e decisivo na medida em que se põe em jogo o sentido último da racionalidade. Sob esse prisma, a tarefa fenomenológica de um retorno às coisas mesmas se reconfigura radicalmente: ela vai gestando e maturando o sentido de uma experiência que é anterior ao simbolismo científico e ao discurso filosófico. A Lebenswelt ou mundo da vida se torna a expressão mais cabal dessa experiência enquanto estrutura concreta, horizonte fáctico ao qual a reflexão é convocada a retornar. Por isso

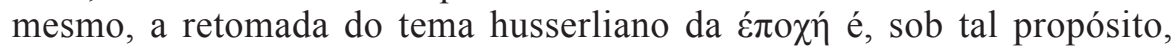
instrutivo no sentido de se medir tanto o seu alcance, quanto o seu limite, como bem avalia Merleau-Ponty:

Todo o mal-entendido de Husserl com seus intérpretes, com os 'dissidentes' existenciais e, finalmente, consigo mesmo provém do fato de que, justamente para ver o mundo e apreendê-lo como paradoxo, é preciso romper nossa familiaridade com ele. Assim, pois, essa ruptura só pode ensinar-nos o brotamento imotivado do mundo. O maior ensinamento da redução é a impossibilidade de uma redução completa (Merleau-Ponty, 1945, p. viii).

Ora, se, conforme Ricœur, a "fenomenologia em seu sentido amplo é a soma da obra de Husserl e das heresias abertas por Husserl [...] ou que ela é, em boa parte, a história das heresias husserlianas" (Ricœur,

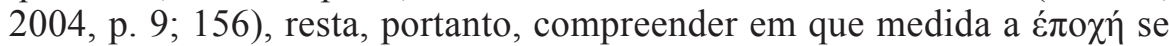
torna o calcanhar-de-aquiles de sua crítica interna? Ou, noutras palavras, em que sentido a facticidade da Lebenswelt se revela como um paradoxo incontornável à própria Razão?

\section{II}

É verdade que, durante muito tempo, e inclusive em textos husserlianos mais recentes, observa Merleau-Ponty, "a redução era apresentada como o retorno a uma consciência transcendental diante da qual o mundo se desdobra em uma transparência absoluta" (Merleau-Ponty, 1945, p. v). Ora, é precisamente essa tese expositiva que encontramos no $\$ 39$ de A Crise das Ciências Europeias no momento em que o tema da Lebenswelt é prestigiado como uma importante conquista da fenomenologia transcendental. O leitmotiv já é conhecido: trata-se de diagnosticar, na ciência moderna, o pathos da perda do sentido pré-operativo do Mundo, sentido 
esse condicionado à verdade matemática. Husserl avoca a necessidade de uma "pura doutrina da essência do mundo da vida" (Husserl, 2008, p. 156) enquanto "um domínio de evidências originárias" (Husserl, 2008, p. 142); fundamento último (Letztbegruendende) do mundo objetivo-científico. O Mundo da vida aqui emergente se torna a figuração emblemática de um "horizonte universal não temático" (Husserl, 2008, p. 159), "intersubjectivamente idêntico para todos" (Husserl, 2008, p. 186). Ao mesmo tempo, admoesta Husserl, essa revelação só ganha evidência última graças à ope-

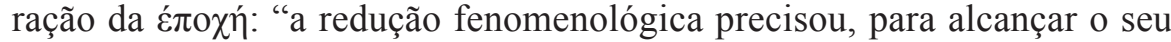
horizonte total, de uma 'fenomenologia da redução fenomenológica"' (Husserl, 2008, p. 259). Husserl advoga, expressamente, que, após a primeira

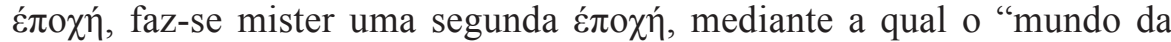
vida" deriva sob a forma de um noema ou correlato. Em tese, a constituição jamais é revogada como princípio de análise, mesmo quando se trata de reconhecer, o próprio mundo, enquanto fundo atemático que a cultura científica teria olvidado. O resultado a que chega a análise intencional, sem nenhuma concessão, admite Husserl, é o de que a "redução" termina por "inibir o valor existencial do mundo da experiência" (Husserl, 2001, p. 53).

Ora, se esse é precisamente o ponto de chegada de Husserl, para Merleau-Ponty tornar-se-á, inversamente, o ponto de partida. Merleau-Ponty redimensiona a importância desse tema ao pôr em questão a compatibilidade, nos quadros do idealismo fenomenológico husserliano, entre o estatuto da Lebenswelt e a exigência da "constituição". Aos olhos de Merleau-Ponty, Husserl se vê forçado a oscilar entre duas direções: de um lado, a ruptura com a atitude natural e, de outro, a compreensão de um fundamento pré-filosófico do homem:

O irrefletido não é nem mantido tal qual, nem suprimido, continua sendo um peso e um trampolim para a consciência. Ele desempenha o papel de um fundante e de um fundado; e refletir é, então, desvelar o irrefletido. Disso é que sobrevém um certo estrabismo da fenomenologia: aquilo que, em certos momentos, explica, é o que está no grau inferior; mas, em outros, ao contrário, o que é superior apresenta-se como uma tese sobre um fundo. A fenomenologia denuncia a atitude natural e, ao mesmo tempo, faz mais do que qualquer outra filosofia por reabilitá-la (Merleau-Ponty, 1995, p. 103-104).

A bem da verdade, Merleau-Ponty observa o quanto Husserl tem consciência do modo como essas duas direções se cruzam. O problema crucial, é que, envolto em tais oscilações ${ }^{1}$, Husserl restaura o cartesianismo,

\footnotetext{
${ }^{1}$ Eis, segundo Merleau-Ponty, as questões que levam Husserl a se embaraçar: "Deve-se passar da doxa à épistémè, ou da doxa à Urdoxa, à doxa primordial? Se a filosofia começa pela atitude natural, nunca sairá dela e, se porventura dela sai, por que razão sai?
} 
pagando um alto preço: a perda da verdadeira dimensão transcendental ${ }^{2}$. $\mathrm{O}$ limite neocartesiano quanto à neutralização da experiência do mundo reside no fato de que a redução ao "metamorfosear de um só golpe o mundo efetivo num campo transcendental, limita-se a me repor na origem de um espetáculo que só pude ter porque, contra minha vontade, eu o organizava" (Merleau-Ponty, 1964, p. 68). Por isso, de nada adianta Husserl fornecer as primeiras descrições da "encarnação" e de seus paradoxos para, logo em seguida, prostrá-las ao poder soberano de um Eu constituinte, reconhecendo nisso, apenas, um enigma (Merleau-Ponty, 1967, p. 185). O flagrante agravante desse limite é o fato de que, ao descrever a Natureza como "a esfera das puras coisas" (Husserl, 1982, p. 50-53), Husserl simplesmente avoca a posição do cientista como observador absoluto. Ou seja, o "nosso Eu, em vez de viver no mundo, se decide a apreender (Erfassen), a objetivar, o que, nessas condições, o Eu se torna 'indiferente' de modo que o correlato dessa indiferença é a pura coisa" (Merleau-Ponty, 1995,

Tais são as questões que agitam Husserl e que explicam as posições contraditórias que ele adota a respeito da constituição da Natureza" (Merleau-Ponty, 1995, p. 112-113). No célebre Colóquio de Royaumont, Merleau-Ponty se reporta novamente ao caráter "tenso" da empresa husserliana, particularmente a dificuldade interna entre a atitude natural e os resultados da reflexão. É que Husserl assinala que "não há redução transcendental que não seja primeiramente redução eidética [...]. Assim, mesmo declarando como irrealizável a ideia de uma redução que não passasse pelo eidos; que, portanto, levaria a vida transcendental da consciência a um grau da perfeita clareza sem ter que passar pelo eidos, ele assinala mais uma dificuldade que uma solução eufórica" (Merleau-Ponty, 1959, p. 158). Ora, volta a problematizar Merleau-Ponty: "essa redução que agora mencionamos como algo fácil de praticar, em todo caso como algo que sabe o que é, não foi sempre apresentada por Husserl como uma espécie de paradoxo e uma espécie de enigma? O fato de que tenha pensado nela ininterruptamente durante vinte e cinco anos parece indicar que a situação da consciência reduzida não é uma situação clara nem fácil de formular. Pode alguém se colocar na atitude da consciência reduzida? Pode instalar-se nela? Parece-me que muitas coisas nos textos de Husserl indicam que isso é um problema para ele. Não se trata simplesmente de uma dificuldade de fato, é um problema de direito. De onde procede essa resistência do irreflexivo à reflexão? Não se pode considerar simplesmente essa resistência como uma adversidade inominável: é o índice de uma experiência que não é a experiência da consciência reduzida, que tem valor e verdade nela mesma e a de que, portanto, terá também que dar conta" (Merleau-Ponty, 1959, p. 158).

2 "Se for isso, recai no déficit cartesiano de uma hipótese da negação (Nichtigkeit) do mundo [...]. Toda negação do mundo, mas também toda neutralidade diante da existência do mundo tem por consequência imediata que se perca o transcendental. A epoché só tem o direito de ser neutralização face ao mundo como em si efetivo, da exterioridade pura: ela deve deixar subsistir o fenômeno desse em si efetivo, dessa exterioridade [...]. Husserl tem razão em dizer que a passagem para a intersubjetividade só é contraditória em face de uma redução insuficiente; mas uma redução suficiente além da pretensa 'imanência' transcendental, conduz ao espírito absoluto" (Merleau-Ponty, 1964, p. 225; 226). 
p. 105). É que, até o fim, Husserl sempre considerou a volta à Lebenswelt "como um procedimento preparatório ao qual deveria suceder a tarefa propriamente filosófica de constituição universal" (Merleau-Ponty, 1960, p. 138-139)33. Ora, sublinha Moura:

No interior da fenomenologia husserliana, a Lebenswelt representa um espaço original, mas não delimita, contudo uma região autônoma, uma região que traga em si mesma a chave de seu sentido. Após delinear o universo do mundo-da-vida, Husserl o caracteriza como etapa a ser igualmente "reduzida" e a partir da qual chegaremos à subjetividade transcendental. Assim, o Lebenswelt é apenas um estágio no caminho em direção à única instância detentora de todo o sentido, ele deve ser igualmente constituído, ele permanece dependente de uma atividade de Sinngebung que não lhe pertence (Moura, 1977, p. 131).

Nesse contexto, mesmo reconhecendo o caráter de originariedade da Lebenswelt, Husserl não lhe outorga uma produtividade mais própria. Essa inconcessibilidade se legitima sob uma cláusula irrevogável da redução: a facticidade da Lebenswelt só pode, quando muito, se desvelar à condição de um simples correlato intencional. Esse condicionamento transcendental - comenta Merleau-Ponty - é reiterado no momento em que Husserl propõe uma segunda redução, em que "as estruturas do mundo da vida devem, por sua vez, ser recolocadas no fluxo transcendental de uma constituição universal, onde todas as obscuridades do mundo seriam esclarecidas" (Merleau-Ponty, 1945, p. 419). Mais uma vez, o problema aqui é que, se o mundo da vida fornece um sentido primitivo, não há porque esse sentido ser esclarecido no âmbito de uma segunda redução, já que

Seria contraditório afirmar, ao mesmo tempo, que o mundo é constituído por mim e que, dessa operação constitutiva, só posso apreender o esboço e as estruturas essenciais. Ora, é preciso que eu veja aparecer o mundo existente, e não apenas o mundo em ideia, no término do trabalho constitutivo, na falta do que só teria uma construção abstrata e não uma consciência concreta do mundo [...]. Eu não sou um pensamento constituinte e meu eu penso não é um eu sou, se não posso, pelo pensamento, igualar a riqueza concreta do mundo e reabsorver a facticidade (Merleau-Ponty, 1945, p. 430-431; 431).

${ }^{3}$ Husserl acena, como tema programático, uma "teoria da experiência antepredicativa" (Husserl, 2000, p. 30). Essa teoria tem por função desvelar um mundo prévio a qualquer operação judicativa, isto é, trazer à tona a experiência de um saber latente, um "pré-saber". Ora, explica o filósofo, "o retorno à experiência antepredicativa e a penetração na camada mais profunda, a camada originária última da experiência antepredicativa, significa uma legitimação da doxa" (Husserl, 2000, p. 53), que, de modo algum, é um domínio de menor dignidade ao da ciência, mas, antes, o domínio "de uma análise originária e de uma fundação subjetiva, da lógica formal tradicional” (Husserl, 2000, p. 60). 
Como Merleau-Ponty evidencia, a flagrante contradição husserliana é a de que, ao desvelar uma significação mais plena do Logos do mundo, o idealismo fenomenológico opera um poder constituinte sobre esse mesmo Logos. Fica, portanto, incompreensível, por que Husserl precisa falar do mundo da vida, justamente no momento em que deixa escapar a sua riqueza mais concreta, isto é, seu domínio originariamente fáctico. Disso advém, sobretudo, a origem do incontornável dilema da descrição eidética: a dupla questão da gênese do mundo existente e da gênese da idealização reflexiva. O nó que acarreta esse problema é que, ao pretender conservar seu papel de disciplina do entendimento,

A reflexão encontra-se, portanto, na estranha situação de exigir e excluir, ao mesmo tempo, um processo inverso de constituição [...]. É o que Husserl punha francamente a nu quando dizia que toda redução transcendental é também redução eidética. Quer dizer: todo esforço para compreender de dentro e a partir das fontes o espetáculo do mundo exige que nos separemos do desenrolar efetivo de nossas percepções e de nossa percepção do mundo. Ou que, ainda, nos contentemos com sua essência; que deixemos de nos confundir com o fluxo concreto de nossa vida para retraçarmos o andamento de conjunto e as articulações principais do mundo sobre o qual ela se abre (Merleau-Ponty, 1964, p. 69-70; 70).

\section{Do mesmo modo, embora}

Reconhecendo que toda reflexão é eidética e que, sob esse aspecto, deixa subsistir o problema de nosso ser irrefletido e daquele do mundo, Husserl não fez mais do que aceitar o problema que a atitude reflexiva comumente evita, a discordância entre sua situação de início e seus fins. Colocando em face do espírito, foco de toda clareza, o mundo reduzido a seu esquema inteligível, uma reflexão consequente faz desaparecer toda questão concernente ao relacionamento entre este e aquele já que, doravante, é pura correlação: o espírito é o que pensa; o mundo é o que é pensado, de modo que não se poderia conceber nem a imbricação de um no outro, nem a confusão de um com o outro, ou, ainda, a passagem de um ao outro e o contato entre eles [...]. A filosofia recusa, pois, como desprovido de sentido, todo entrelaçamento do mundo com o espírito e do espírito com o mundo. Está fora de questão $\mathrm{o}$ fato de que o mundo possa preexistir à minha consciência do mundo: não é evidente que o mundo todo sem mim, em que eu possa pensar, vem a ser, por esse fato mesmo, mundo para mim. Também não fica evidente que o mundo privado que adivinho na origem do olhar do outro não é assim tão privado. Ou que, ainda nesse mesmo momento, eu não me transforme em seu quase-espectador? (Merleau-Ponty, 1964, p. 71; 71-72).

Aos olhos de Merleau-Ponty, há, na verdade, um ponto cego de toda redução: o de que "a filosofia não se completa com o retorno ao eu" 
(Merleau-Ponty, 1945, p. vii). Ora, qualquer regresso à consciência (em seu sentido mais absoluto) reincidirá, inevitavelmente, num limite dificilmente contornável e que todo idealismo terá, implacavelmente, com que se defrontar. Merleau-Ponty mostra o quanto Husserl, volta e meia, teria pressentido tal dificuldade. Mais do que isso: em sua obra tardia, o fundador da fenomenologia parece estar bem mais cônscio desse caráter aporético ou paradoxal que insiste em rondar a análise constituinte face à experiência sensível, deixando entrever nessa experiência a possibilidade de uma interrogação mais radical:

À medida que Husserl passa à execução de seu programa, ele traz à luz os fragmentos de ser que desconcertam sua problemática: nem o corpo enquanto "sujeito-objeto"; nem a passagem do tempo interior que deixa de ser um sistema de atos de consciência; nem outrem que nasce por elevação sobre mim ou pela expansão de mim como Eva nasce de uma costela de Adão; nem a história, que é minha vida no outro e a vida do outro em mim que é, por princípio, como o outro, um "objeto" inexato, não se deixam conduzir sob a correlação da consciência e de seus objetos, da noese e do noema. A filosofia deixa de ser conhecimento exato, olhar puro sobre os objetos puros: ela é, diz Husserl, "aquilo que se quer" através das gerações de filósofos nas quais ninguém coincide com a "interioridade intencional" que todos eles invocam e que constituem em conjunto. Toda consciência é consciência de algo ou do mundo, mas esse algo, esse mundo, já não se torna mais, como parecia doutrinar o "positivismo fenomenológico", um objeto que é o que ele é exatamente ajustado aos atos de consciência. A consciência é, agora, a "alma de Heráclito", e o Ser, que está antes em torno que diante dela, é um Ser onírico, por definição, oculto. Husserl disse algumas vezes: um "pré-ser" (Merleau-Ponty, 2000, p. 280-281).

E lá, em Le Philosophe et son Ombre, Merleau-Ponty ajuíza:

Desde as Ideias (II) parece claro que a reflexão não nos instala num meio fechado e transparente, não nos faz passar, pelo menos imediatamente, do "objetivo" para o "subjetivo", tendo antes por função desvelar uma terceira dimensão em que essa distinção torna-se problemática (Merleau-Ponty, 1960, p. 205)4.

Como vemos, Merleau-Ponty parece identificar, na última obra de Husserl, algo que desconcerta o trabalho puramente reflexivo. Há um fundo irrefletido, ou seja, uma terceira dimensão, aquém da cisão entre o em-si e o para-si; dimensão que parece resistir, intrepidamente, a qual-

${ }^{4}$ Ao parafrasear as Ideias (II), Merleau-Ponty afirma que, "num sentido, toda reflexão é incapaz de apreender o irrefletido, porque ela não é mais o irrefletido. Ele faz desta dificuldade uma resposta: o fato, a situação filosófica inicial é que reflito sobre algo que é prévio à reflexão, mas só tenho noção deste irrefletido, através do movimento pelo qual tento retomar e refletir" (Merleau-Ponty, 2000, p. 333). 
quer condicionamento egológico. Nessa direção, malgrado a cláusula da $\varepsilon \dot{\pi} \pi \chi \eta ́$, Merleau-Ponty revisita em Husserl algo que parece acompanhar implacavelmente o filósofo, isto é, sua "sombra". Merleau-Ponty cunha essa metáfora para indicar o que permanece sempre ao redor do pensamento como um fundo obscuro da reflexão. Husserl teria escavado esse fundo como uma dimensão arqueológica, uma espécie de subsolo do pensamento que, no entanto, permanecera intacto, obliterado sob a penumbra da razão, ou seja, o seu impensado ou subentendido de base. Por isso, a sombra que acompanha inseparavelmente o filósofo não é a ausência da luz natural (a razão), mas a dimensão que sem a qual, não há luz. A sombra metaforiza essa dimensão de obscuridade que sempre recobre a linguagem e o pensamento. É o vestígio não apenas circunscrito, atrás do prestigioso exercício de reflexão, mas a auréola circundante acerca do que ainda não foi suficiente ou radicalmente refletido. Ela é, por assim dizer, o irrefletido e, nessa medida, o movimento ou experiência a que somos arrastados enquanto falamos ou pensamos. Como a cauda de um cometa, a Sombra é o prolongamento de um Ser de práxis, a extensão mesma do Mundo da vida em sua figuração primeira. Como uma "bruma de vida anônima", a Sombra encena a experiência de um Ser englobante que funda nosso vínculo consanguíneo com o mundo e com outrem. Sem essa práxis, sem essa simbologia primordial, a reflexão, o conceito, a própria redução jamais perfariam sua operação mais própria.

Ora, em A Crise das Ciências Europeias, Husserl anteviu que o fenômeno da crise da ciência decorria diretamente desse não reconhecimento simbólico ou, ainda, obscuramente anônimo de uma experiência que parece, por princípio, desconcertar a própria reflexão. Na verdade, a descoberta da Lebenswelt como expressão desse simbolismo primordial ou fundo atemático não apenas diagnosticará o limite tenso da empresa fenomenológica husserliana. Essa descoberta parece perspectivar uma alternativa considerável. É assim que, em seu curso ministrado entre 1959 e 1960, no Collège de France, Husserl aux Limites de la Phénoménologie, Merleau-Ponty revive esse debate não se abstendo, ao mesmo tempo, de prescrever um remédio para a crise diagnosticada do saber europeu: o antídoto não é outro senão o de promover uma "meditação (Besinnung) histórica a fim de revelar a fundação originária (Urstiftung) e todos seus horizontes. Trata-se de desvelar a Lebenswelt, o ser de horizonte" (Merleau-Ponty, 1998, p. 37). É notório o quanto Merleau-Ponty reitera, sucessivas vezes, essa incursão fenomenológica a um "espaço ontológico" cujo estatuto é "pré-ideal" (Merleau-Ponty, 1998, p. 31). A Lebenswelt à qual todo saber deve retornar é a insígnia, por excelência, que não se reduz a um modelo de Ser solipsista ("Ser ideal intemporal") (Merleau-Ponty, 1998, p. 38) absorvido numa síntese subjetiva, mas é o que acena um 
horizonte aberto enquanto mundo circundante (Umwelt) (Merleau-Ponty, 1998, p. 91), campo comum do qual participamos. A Lebenswelt se torna essa via selvagem, quer dizer, a camada primordial do sensível que ainda não fora arqueologicamente desbravada. Trata-se de um mundo barroco; a própria irrupção de um Ser em estado bruto não depurado mediante uma operação absolutamente reflexiva. Por isso, sua significação é, ontologicamente, primordial, pré-empírica ${ }^{5}$, ou seja, o Mundo da vida é esse Ser Bruto ou horizonte selvagem enquanto experiência estética radicalmente originária. É lançando mão dessa terminologia que Merleau-Ponty apropriará de Husserl outra curiosa expressão como insígnia de seu projeto de uma nova ontologia: o "Logos do mundo estético". Ora, qual o alcance semântico desse termo?

\section{III}

Ao restituir a teoria husserliana da intencionalidade, Merleau-Ponty destaca dois níveis de abordagem: uma "intencionalidade em ato" instituída como operação constituinte da síntese temporal e uma "intencionalidade operante ou latente" (Fungierende Intentionalität), compreendida enquanto condição de possibilidade da primeira. Ora, é notável que o acento merleau-pontyano incidirá mais pontualmente sobre esse segundo nível da esfera intencional comentada por Fink, como um domínio que "poderia ser constituído em relação a uma camada mais profunda" (Merleau-Ponty, 2000, p. 233). A expressão cunhada por Husserl a fim de descrever a estrutura mais elementar dessa camada é a que, lapidarmente, encontramos em Formale und transzendentale Logik: trata-se - exprime ele - de um Logos primordial (Urlogos) (Husserl, 1992, p. 280), ou Logos do mundo estético (Logos der ästhetischen Welt) (Husserl, 1992, p. 297). Esse Logos se inscreve como uma espécie de arte oculta: uma arte viva e operante, prévia a toda tese ou juízo ${ }^{6}$. A intencionalidade operante é justamente essa arte capaz de resistir a toda operação reflexiva, subjetiva e puramente conceitual. Merleau-Ponty comentará esse exercício estético como um movimento de deflagração daquele fato primitivo (Lebenswelt) que a tradição filosófica se esforçava por definir e que, no entanto, acabara por lhe escapar completamente. Tudo se passa como se, em suas últimas reflexões, Husserl vislumbrasse um novo horizonte atemático e resistí-

5 Trata-se de um "mundo pré-ideal (não mundo sensível dos empiristas, unicamente, mas também o mundo histórico: a Lebenswelt envolve tudo)" (Merleau-Ponty, 1998, p. 81).

${ }^{6} \mathrm{Ou}$, parafraseando Heidegger: “transcendência” (Heidegger, 1986, p. 351-367). 
vel, por princípio, a toda neutralização. Merleau-Ponty, a esse propósito, chega até mesmo a esboçar, numa nota inédita de 1959: "admitimos uma espécie de 'redução': não redução no sentido (em que, por inversão, seria um sistema de Sinngebung), mas redução à Weltthesis pré-pessoal e meta-pessoal, ao "há'" (Merleau-Ponty, 1992, s/p, apud Barbaras, 1998, p. 78). $\mathrm{O}$ que essa passagem põe a nu é que Merleau-Ponty quer pensar com Husserl, para além de Husserl. Se quisermos ainda fazer uso do vocabulário da redução, será o de a reconceituar como retorno não a uma imanência egológica pura, mas à transcendência do mundo como "há", como camada pré-operativa, terceira dimensão, aquém do sujeito e do objeto. Noutra curiosa passagem de Signes, Merleau-Ponty esclarece melhor o uso deliberado dessa subversão semântica: a 'redução à 'egologia' ou à 'esfera do pertencer', como toda redução, não passa de uma prova dos vínculos primordiais, uma maneira de segui-los até os seus derradeiros prolongamentos" (Merleau-Ponty, 1960, p. 221). O que Merleau-Ponty atesta é o fato fundamental de que a redução não se desprende de seu elo primordial com o Mundo da vida enquanto camada ou Ser de transcendência. Por isso, o único retorno legítimo será aquele que não permaneça indiferente àquela que é a pátria de toda racionalidade: a região ancestral da Lebenswelt. Nessa perspectiva, a melhor fórmula da redução é, antes, aquela proposta por Fink, quando se reportava à atitude de uma "admiração diante do mundo" (Fink, 1933, p. 331ss, apud Merleau-Ponty, 1945, p. viii). Isso significa que, diferentemente do idealismo transcendental kantiano (que, ainda, reincidia numa "filosofia mundana" ao tornar o mundo imanente ao sujeito), trata-se de "admirar-se" do mundo em sua experiência mais radicalmente concreta. A redução deixa de ser um recuo à esfera do "próprio", isto é, o movimento de uma "transcendência na imanência" (Husserl, 1976, p. 124) idealmente condicionado. Como bem observa Zielinski, em Merleau-Ponty, a redução exprime "uma reciprocidade dinâmica, ininterrupta, uma afecção mútua sem oposição - onde a redução pode me doar o mundo, não unicamente como fenômeno, mas também numa perspectiva ontológica" (Zielinski, 2002, p. 17). Sob esse prisma, o mundo sensível se projeta como uma exterioridade irredutível, um Logos transcendente aos atos intencionais. É levando em conta essa revisão crítica que Merleau-Ponty, desde o início de sua obra, deflagrara a incontornável "incompletude" intrínseca à operação husserliana da redução: essa se torna um conceito limite face à opacidade e à transcendência do mundo, já que o que realmente importa, é "refletir sobre a transcendência do mundo como transcendência" (Merleau-Ponty, 1964, p. 61). $\mathrm{O}$ único movimento fenomenológico legítimo terá que fazer um caminho inverso, ou seja, trazer à tona a fulguração de um Logos do sensível que é prévio à síntese eidética, pois: 
Se Husserl mantém-se firme nas evidências da constituição, não é por loucura da consciência [...] é porque o campo transcendental deixou de ser somente o dos nossos pensamentos para tornar-se o da experiência total; é porque Husserl confia na verdade na qual estamos desde o nascimento, e que deve poder conter as verdades da consciência e as da Natureza (Merleau-Ponty, 1960, p. 224).

Merleau-Ponty pondera que, se as relações “entre o 'mundo' da cons-ciência pura (resultado da redução fenomenológica) e o mundo das unidades transcendentes constituídas nela" (Husserl, 1982, p. 293) se incompatibilizam, é por que, de fato, a constituição já não pode se manter neutra àquela "tese anterior a toda tese". Ou seja: a operação reflexiva não pode tornar-se impermeável àquele " há' prévio" enquanto "solo do mundo sensível e do mundo trabalhado tais como são em nossa vida, por nosso corpo" (Merleau-Ponty, 1985, p. 12-13). Desse modo, "o espírito em sentido primeiro não é o Eu absoluto de Sinngebung" (Merleau-Ponty, 1998, p. 92), mas, fundamentalmente, "o mundo sensível no qual se apoia o mundo ideal" (Merleau-Ponty, 1998, p. 69). A tarefa, pois, consiste em compreender que toda idealização só se efetiva sobre uma dimensão mais profunda e englobante: a de um "Ser intersubjetivo" (Merleau-Ponty, 1998, p. 25). Ora, trata-se, aqui de um "ser inteiro, em carne e osso" (Merleau--Ponty, 1998, p. 31) como Ser de práxis, circunscrito no horizonte de nossa "encarnação sensível” (Merleau-Ponty, 1998, p. 39). É esse solo de um mundo mais original que se trata de escavar (Merleau-Ponty, 2000, p. 219), prefigurado por Husserl como um "mundo selvagem e um espírito selvagem" (Merleau-Ponty, 1960, p. 228). Ou, ainda, a Natureza, em seu sentido primeiro e originário do termo (Husserl, 1982, p. 230) ${ }^{7}$. Ora, que papel exatamente o conceito merleau-pontyano de natureza cumpre nessa tarefa arqueológica de um retorno ontológico? Tratar-se-ia, aqui, de mais uma filosofia da natureza, em seu formato tradicionalmente metafísico? É possível interpelar outra ideia de Natureza, sem se tornar vítima da ilusão retrospectiva do naturalismo?

\section{IV}

Os cursos sobre a natureza ministrados no Collége de France entre os anos de 1956 a 1960 perspectivam uma amostra viva dessa tarefa

7 "Existe uma universalidade primeira da sensação. O universal não é o conceito, mas essa percepção em carne e osso, fundamento da minha relação com os outros" (Merleau-Ponty, 1995, p. 112). 
programática. Merleau-Ponty confere viva audiência ao tema da natureza buscando explicitar, sobretudo, o quanto a ciência e a filosofia devem ser interrogadas a partir de suas próprias origens. Nessa direção, a tarefa filosófica dos tempos atuais deve buscar aquilo que constitui a "auto-produção de um sentido" (Merleau-Ponty, 1995, p. 19), isto é, o "sentido primordial, não lexical" (Merleau-Ponty, 1995, p. 19) como desenvolvimento imanente do conhecimento objetivo, do corpo, da intersubjetividade. Para além do ideal de uma Natureza pura será preciso conferir um lugar mais próprio ao "conhecimento da natureza em seus primórdios" (Merleau-Ponty, 1969, p. 160). É só mediante a retomada radical e o consequente aprofundamento dessa empresa que poderemos alçar outro sentido da racionalidade e, por extensão, da própria Natureza - não a "natureza fora de nós", mas aquela que "vivemos do interior", isto é, "de dentro" (Merleau-Ponty, 1995, p. $20 ; 267 ; 275)$.

É essa enunciação radicalmente decisiva que Merleau-Ponty visa explorar, no contexto de tais cursos, avocando a exigência de fundar uma "ontologia da natureza como via para a própria ontologia" (Merleau-Ponty, 1995, p. 265). Isso implica a necessidade de um retorno à questão da Natureza em sua radicalidade ontológica última. Ora, qual é o real significado desse regresso? Digna de registro nesses cursos é a reconstitutiva referência de Merleau-Ponty a uma tradição de autores como Schelling, Bergson, Husserl e Whitehead, que instituíram, cada qual, uma determinada concepção de natureza. Entre essas referências, a figura de Schelling é substancialmente sugestiva na medida em que Merleau-Ponty resgata, do projeto schellinguiano da Naturphilosophie, a possibilidade de refletir o irrefletido, isto é, de vislumbrar o principio bárbaro de uma "fenomenologia do Ser pré-reflexivo" (Merleau-Ponty, 1995, p. 66). Mais do que isso: Merleau-Ponty mostra que o retorno a uma Natureza Primordial (Erste Natur) avocado por Schelling visa explorar uma relação capital entre a Natureza e a Vida. É que Schelling aposta numa produtividade ou eficácia mais própria da Natureza: ela passa a ser o horizonte de toda reflexão, tornando, radicalmente, plausível "pensar uma vida da Natureza" (Merleau-Ponty, 1995, p. 76) como fato último e contingente. Ela será, ao mesmo tempo, passiva e ativa, produto e produtividade. Deixa de se presumir, nesse instante, qualquer intervenção sobre a Natureza por obra e graça de um Eu Absoluto. Nesse sentido, inexiste uma Natureza sem qualquer autonomia e desprovida, portanto, de força. É mediante essa perspectiva mais ampla que Schelling pode reconhecer na Natureza seu princípio de indivisão que tanto viria chamar a atenção de Merleau-Ponty. Schelling, noutra bela fórmula um tanto enigmática, assim enuncia: "A natureza deve ser o espírito visível, o espírito a natureza invisível" (Schelling, 2001, p. 115). Ora, essa outra Natureza aqui em questão já não 
é mais aquela plantada na base de uma ipseidade, uma egoidade absoluta, isolada e destacada das coisas. Schelling pretende, na verdade, abrir outro caminho, diverso do idealismo, em que toma curso uma dialética radical capaz de deflagrar a contradição e a negação como princípio criador. Em meio a esse horizonte, a Natureza é incoercível ao puro entendimento e suas leis. Aquém da razão e da reflexão há, portanto, uma força expansiva, um "ser original indivisível" (Schelling, 1949, p. 32), uma via original ou uma espécie de "chama infatigavelmente movente" (Schelling, 1949, p. 48) a que Heráclito já aludia quando punha em marcha a contradição em seu movimento mais plástico. Ora, "sem contradição", assegura Schelling, "não haveria nem vida, nem movimento, nem progresso, mas repouso eterno. Todas as forças dormiriam num sono de morte" (Schelling, 1949, p. 34). Recusar esse princípio de oposição, genuinamente criador, é exilar letargicamente a natureza à condição de "eterna imobilidade, absoluta inatividade" (Schelling, 1949, p. 42). É exatamente essa compreensão que Schelling dá vazão quando atesta que "na medida em que sou idêntico à Natureza, compreendo-a tão bem quanto a minha própria vida" (Schelling, 1946, p. 80).

É em meio a esse princípio de coesão, originariamente inscrito no seio da experiência mais ampla da Natureza, que Merleau-Ponty passa a abrir uma via privilegiada de interrogação ontológica na qual o logos do mundo cultural e a própria intersubjetividade se inscrevem esteticamente. É visando tal propósito que a figura de Husserl é aproximada do contexto romântico da ideia de natureza, retornando à cena filosófica, mais uma vez:

Husserl procura um fundamento "estético" e reabilita uma filosofia da Natureza, uma membrura do mundo percebido. Ela jamais se apresenta como uma natureza-causa da qual seríamos os efeitos [...]. Assim, os sujeitos não são iniciadores, puras interioridades em face das coisas. A Natureza é este acaso ofertado à corporeidade e à intersubjetividade (Merleau-Ponty, 2000, p. 231-232).

Como vemos, o que Merleau-Ponty identifica na obra de Husserl e que Schelling já teria pressentido é a maturação de uma ideia de natureza que busca desprender-se, ao máximo possível, da concepção clássica de natureza, em sua versão metafísica, enquanto omnitudo realitatis. Husserl descreve a Natureza como "totalidade dos objetos que podem ser pensados originariamente e que, para todos os sujeitos comunicantes, constitui um domínio de presença originária" (Merleau-Ponty, 1960, p. 216). Quer dizer, Husserl traz à tona outro sentido da Natureza como um Ser englobante, "um gênero de ser no qual já nos descobri- 
mos investidos antes de toda reflexão" (Merleau-Ponty, 1995, p. 118). É, nesse sentido, que se pode afirmar que ele "entrevê, pelo menos, atrás da gênese transcendental, um mundo onde tudo é simultâneo" (Merleau--Ponty, 1960, p. 226) ${ }^{8}$. Mundo de cujo Logos reflete nossa comunhão carnal e irrefletida com o sensível, aquém de toda idealização reflexiva. Rumo a essa nova direção, o caminho que conduz à Lebenswelt deverá ser novamente percorrido. O que implica, radicalmente, "abandonar, a esse modo, a filosofia da Erlebnisse e passar à filosofia da nossa fundação originária (Urstiftung)" (Merleau-Ponty, 1964, p. 275) como um "campo" de abertura em que a "subjetividade não é mais ser para si de início" ou pura "doação de sentido (Sinngebung)" (Merleau-Ponty, 2003, p. 103). Nessa reviravolta, "a atitude natural e a atitude transcendental não são dois conjuntos de atos de sentido oposto. A relação originária que entretemos com o mundo não é uma 'atitude', isto é, um conjunto de atos, mas uma fé primordial, uma Urdoxa" (Dastur, 2001, p. 83). Ao inverter o programa fenomenológico da analítica transcendental, Merleau-Ponty reaviva outra exigência radical: a de um retorno à ontologia; uma ontologia do Ser Bruto como Logos fundamental. Ela se traduzirá no projeto de "uma reabilitação ontológica do sensível" (Merleau-Ponty, 1960 , p. 210), uma restituição da Natureza em seu sentido primordial, reorientando, portanto, outra significação da Lebenswelt.

\section{V}

A nouvelle ontologie em curso será aquela que deverá abrir outra via de incursão rumo à Lebenswelt, quer dizer, desbravar uma experiência selvagem do sensível, do mundo em estado bruto e arcaico antes da reflexão. Ora, Merleau-Ponty mostra que essa tão pretendida incursão é perpassada por um investimento ontologicamente corporal e intercorporal. É sob esse giro reflexivo que a obra de Merleau-Ponty credita, desde o início, um estatuto mais proeminente à problemática do corpo. O filósofo passa a

8 "Projeto de posse intelectual do mundo, a constituição torna-se cada vez mais, à medida que vai amadurecendo o pensamento de Husserl, o meio de desvelar um reverso das coisas que não constituímos. Era preciso essa tentativa insensata de tudo submeter às formalidades da 'consciência', ao jogo límpido de suas atitudes, de suas intenções, de suas imposições de sentido - era preciso concluir o retrato de um mundo sábio que a filosofia clássica nos tem deixado - para revelar todo o resto: esses seres, aquém de nossas idealizações e de nossas objetivações, que as nutrem secretamente, e em que temos dificuldade de reconhecer noemas: a Terra" (Merleau-Ponty, 1960, p. 227). 
explorar, numa inspiração oriunda de Husserl, que o corpo é uma experiência transfigurante e, ao mesmo tempo, variante de um enigma mais vasto: o próprio Logos do mundo estético. Como, então, essa perspectiva pode se elaborar? A fim de descrever o movimento de transcendência operado pelo corpo, Merleau-Ponty busca desconstruí-lo para além das concepções psicológicas clássicas. Trata-se de descrever a corporeidade a partir de sua figuração intencionalmente operante; o corpo se torna uma espécie de potência irracional. Ele é o veículo do ser no mundo; é um ser expressivo de múltiplas dimensões (afetiva, linguística, etc). É essa formulação que encontramos no período onto-fenomenológico do filósofo nos escritos iniciais. Já, a partir de meados dos anos 50, inclusive, nos cursos consagrados ao tema da natureza, Merleau-Ponty passa a aprofundar o caráter último da experiência corporal a partir de sua significação mais operante e atual. Como bem observa Zielinski: "A corporeidade é o primeiro índice de um enigma que define a imanência. Ser ao mundo é, de início, visar o mundo por seu corpo [...]. O corpo põe a questão da impossibilidade de romper com o mundo, ao mesmo tempo, que a questão da possibilidade de uma transcendência" (Zielinski, 2002, p. 46). Essa transcendência aqui radicalizada entre o vinculum entre o corpo e o mundo, é o que permite reformular, em termos merleau-pontyanos, o estatuto da doação. Assim, a dinâmica do corpo não se realiza mediante uma decisão absoluta do espírito, mas anuncia, paradoxalmente, um "enigma" essencial:

O enigma é que meu corpo é, simultaneamente, vidente e visível. Ele que olha todas as coisas, também pode se olhar e reconhecer naquilo que vê o "outro lado" de sua potência vidente. Ele se vê vendo, toca-se tocando, é visível e sensível para si mesmo. Ele é um si não por transparência como o pensamento que só pode pensar assimilando o pensado, constituindo-o, transformando-o em pensamento. Mas é um si por confusão, narcisismo, inerência daquele que vê naquilo que vê, daquele que toca naquilo que toca, do senciente ao sentido. É, portanto, um si tomado entre as coisas, o qual possui uma face e um dorso, um passado e um porvir [...]. Visível e móvel, meu corpo conta-se entre as coisas, é uma delas, preso no tecido do mundo e dotado da coesão de uma coisa. Mas, porque vê e se move, mantém as coisas circulando ao seu redor, pois elas constituem um anexo ou um prolongamento dele mesmo, estão incrustadas em sua carne, fazendo parte de sua definição plena, já que o mundo é feito do mesmo forro que o corpo (Merleau-Ponty, 1985, p. 18-19).

Em Le Philosophe et son Ombre, essa metamorfose ressurge mediante dois níveis concêntricos, pois há uma

[...] relação de meu corpo consigo mesmo que o transforma no vinculum do eu com as coisas. Quando minha mão direita toca a esquerda, sinto-a como uma "coisa física", mas no mesmo instante, se eu quiser, um acontecimento 
extraordinário se produz: eis que minha mão esquerda também se põe a sentir a mão direita [...] Dessa maneira, porque eu me toco tocando, meu corpo efetua "uma espécie de reflexão". Nele e por ele não há somente relação em sentido único daquele que sente com aquilo que ele sente. A relação se inverte: a mão tocada torna-se tocante, de modo que sou obrigado a dizer que o tato aqui está espalhado pelo corpo, que o corpo é "coisa senciente", "sujeito-objeto" (Merleau-Ponty, 1960, p. 210).

Ao mesmo tempo - volta a ilustrar Merleau-Ponty - há uma amplificação do mesmo paradoxo:

Se, ao apertar a mão de outro homem, tenho a evidência de seu ser-aí, é porque ela se coloca no lugar de minha mão esquerda: meu corpo se anexa ao corpo do outro nesta "espécie de reflexão" da qual ele é paradoxalmente a sede. Minhas duas mãos são "co-presentes" ou "coexistem" porque são as mãos de um só corpo: o outro aparece por extensão dessa co-presença. Ele e eu somos como os órgãos de uma só intercorporeidade (Merleau-Ponty, 1960, p. 212-213).

Merleau-Ponty mostra que, nessa "iniciação e abertura a um mundo táctil, o "sujeito que toca' passa ao nível do tocado" (Merleau-Ponty, 1964, p. 176), quer dizer, o corpo organiza uma espécie de "síntese de transição"; ele refaz, com o corpo de outrem e com a carne do mundo, uma só coesão estética, uma só unidade carnal. Nessa mútua perspectiva,

Se minha mão esquerda toca minha direita e se de repente quero, com a mão direita, captar o trabalho que a esquerda realiza ao tocá-la, esta reflexão do corpo sobre si mesmo sempre aborta no último momento: no momento em que sinto minha mão esquerda com a direita, correspondentemente paro de tocar minha mão direita com a esquerda (Merleau-Ponty, 1964, p. 24).

O que se presencia nessa espécie de experiência "sobrerreflexionante" do corpo é uma "reversibilidade sempre iminente e nunca realizada de fato, pois minha mão esquerda está sempre em vias de tocar a direita no ato de tocar as coisas, mas nunca chego à coincidência; eclipsa no momento de produzir-se" (Merleau-Ponty, 1964, p. 194). Merleau-Ponty desconstrói, nesse plano, qualquer aparato absolutamente realista ou substancialista junto à práxis do corpo. $\mathrm{O}$ que a reversibilidade do corpo revela é, antes, o enigma ou paradoxo de um entrelaçamento vivo, difundido, portanto, numa mesma "zona de transcendência" com o outro pelo seu corpo e com o mundo. No movimento de reversibilidade há concentricidade, transgressão de fronteiras, coexistência selvagem, reciprocidade dimensional, cumplicidade operante, sublimação mútua de tecidos. 
Assistimos, desde então, a experiência de uma dupla inscrição "dentro" e "fora", isto é, o mistério de um acasalamento sensorial, uma dialética entre a atividade e a passividade, que faz com que o corpo, longe de ser um fato empírico, exprima, em última análise, um valor ontológico em sentido radicalmente originário. Como bem observa Gély, "há um sentir único que se tem lá entre as duas mãos [...]. Sua atividade é sua passividade e sua passividade é sua atividade" (Gély, 2000, p. 64). Ora, nesse intercurso, descreve Merleau-Ponty, "em vez de rivalizar com a espessura do mundo, a de meu corpo é, ao contrário, o único meio que possuo para chegar ao coração das coisas, fazendo-me mundo e fazendo-as carne" (Merleau-Ponty, 1964, p. 178). Quer dizer, "cada um dos seres é para o outro arquétipo, pois o corpo pertence à ordem das coisas, da mesma forma que o mundo é carne universal" (Merleau-Ponty, 1964, p. 181).

Como vemos, era essa simultaneidade que Husserl chegara a entrever como uma relação recíproca entre a Natureza, o corpo e a alma (Merleau-Ponty, 1960, p. 223). Uma espécie, digamos, de circularidade entre a corporeidade e a sensibilidade do mundo, já que ambos são, de pleno direito, enigmas alusivos, uma vez que "tudo o que se diz do corpo sentido repercute sobre todo o sensível de que faz parte e sobre o mundo" (Merleau-Ponty, 1964, p. 182). O corpo torna-se um sensivel exemplar, o índice de uma ontogênese inscrita no próprio logos do mundo como Lebenswelt em sua acepção mais profundamente consanguínea ou carnal. Sob esse prisma, se "a carne do corpo nos faz compreender a carne do mundo" (Merleau-Ponty, 1995, p. 280), é porque também por meio da própria "carne do mundo, que se pode, enfim, compreender o corpo próprio" (Merleau-Ponty, 1964, p. 304). Ora, mas, afinal que "Carne" é essa que torna compreensível não só o corpo, mas o sentido último da reflexão? (Cf. Silva, 2009).

\section{VI}

Merleau-Ponty adverte que o caráter reflexionante do corpo não se realiza num circuito fechado, restrito apenas aos movimentos gestuais. A reflexividade é o que traduz, admiravelmente, um movimento de abertura, difundindo-se numa dimensão sinérgica mais ampla e inesgotável. Trata-se, portanto, de uma reversibilidade mais geral que se propaga ou se multiplica numa profusão de experiências. O Lebenswelt é essa dimensão de base, ou seja, a camada de intersensorialidade total que reveste, por assim dizer, toda consanguinidade intercorporal, carnal. Ora, é esse caráter dimensional mais amplo que Merleau-Ponty passa a reconceituar, a partir 
do "último" Husserl1", via a noção de Carne. É assim que, em Le Visible et l'Invisible, o filósofo daria vazão a várias significações concêntricas dessa noção nuclear advertindo que jamais se deve confundi-la com certos conceitos oriundos da metafísica clássica tais como matéria, espírito ou substância. A noção de carne, aqui fulgurada, se aproxima mais daquele sentido pré-socrático da noção de elemento que os gregos enunciavam quando se reportavam a uma significação mais abrangente e originária da physis. Seguindo essa acepção, a Carne é o emblema concreto de uma maneira de ser geral; numa palavra: facticidade (Merleau-Ponty, 1964, p. 184; 193-194). Ela é o "ciclo completo" (Merleau-Ponty, 1964, p. 313) ou uma espécie de "textura aderente", o "tecido comum de que somos feitos" (Merleau-Ponty, 1964, p. 257), cuja virtude singular "atapeta e até mesmo envolve todas as coisas visíveis e tangíveis" (Merleau-Ponty, 1964, p. 164). Enquanto uma "massa interiormente trabalhada" (Merleau--Ponty, 1964, p. 193), ela é a "localidade global" ou nossa "circunvizinhança geral", ou seja, o próprio "meio formador do objeto e do sujeito" (Merleau-Ponty, 1964, p. 193). O que Merleau-Ponty visa unificar em cada uma dessas significações é a ideia segundo a qual a Carne traduz uma espécie de Logos do Ser Bruto. Ela é a emergência de um "campo sempre aberto" (Merleau-Ponty, 1964, p. 239), é o "tecido de nossa vida, onde assistimos por dentro a deiscência, análoga à de meu corpo, que o abre para si mesmo e nos abre para ele" (Merleau-Ponty, 1964, p. 157). É nesse sentido mais amplo que a Carne é a fórmula ou expressão mais emblemática do próprio Logos do sensível portador de uma fecundidade sui generis: o Ser é "o que exige de nós criação para que dele - enquanto criação - tenhamos experiência" (Merleau-Ponty, 1964, p. 251).

Merleau-Ponty redefine o Ser como um Ser de práxis: assim, no momento em que o artista retrata seu quadro, faz reviver, pelo enigma de seu gesto corporal, o próprio mistério do logos do sensível. Trata-se, aqui, do enigma de um exercício ontologicamente criador. A gestualidade corpórea do pintor, muito mais que meramente objetivar ou representar, aprofunda uma intimidade com a natureza em estado selvagem (Cf. Silva, 2010). Por isso, criar é experimentar a dádiva do sentido último da encarnação. É refazer, noutro nível, a dialética do visível e do invisível, segregando a experiência de um Ser de indivisão enquanto experiência integral entre o corpo e o logos do mundo.

9 "A carne" - observa Barbaras - "não caracteriza um modo de doação; ela é, antes, a presença originária sobre o fundo da qual toda doação pode ser pensada" (Barbaras, 1998, p. 85). A propósito da emergência do conceito de "carne" em Husserl, ver ainda os primorosos trabalhos de Franck (1981) e de Depraz (1995). 
O que a experiência pictórica, exemplarmente, perspectiva é o retorno à Lebenswelt enquanto "horizonte de um novo tipo de ser" (Merleau-Ponty, 1964, p. 195). Tudo se passa como se o pintor adentrasse ou escavasse, incansavelmente, uma experiência selvagem da cultura e da arte como obra. A linguagem também se projeta em meio a esse caminho já que, como diz Merleau-Ponty, ela faz com que o mundo manifeste a "possibilidade de ser evidente em silêncio, de ser subentendido" (Merleau-Ponty, 1964, p. 267). O que no mundo da vida há de enigmático é, paradoxalmente, a capacidade de "exceder" nossos hábitos intelectuais, dando voz, pela carne da linguagem, a esse "fato inaugural", laboriosamente fecundo. O Logos do mundo estético enquanto Carne é o fundo em que se põe o espectador puro, a fonte mais fecunda e inesgotável, desde onde, o trabalho reflexivo se alimenta. Nessa direção, o retorno à Lebenswelt é, em análise última, a expressão máxima dessa nouvelle ontologie como projeto e tarefa a ser perseguida. O Mundo da vida enquanto Carne é a verdade do naturalismo, ou seja, a tese constante e primordial de um Logos preexistente à Razão que Husserl prefigurava como tema primeiro da fenomenologia.

\section{REFERÊNCIAS BIBLIOGRÁFICAS}

BARBARAS, R. Le tournant de l'expérience: recherches sur la philosophie de Merleau-Ponty. Paris: Vrin, 1998.

DASTUR, F. Chair et langage: essais sur Merleau-Ponty. Paris: Encremarine, 2001.

DEPRAZ, N. Transcendance et incarnation: le statut de l'intersubjectivité comme alterité a soi chez Husserl. Paris: Vrin, 1995.

FINK, E. Die phänomenologische Philosophie Husserls in der gegenwärtigen Kritik, Kantstudien, 1933.

FRANCK, D. Chair et corps: sur la phénoménologie de Husserl. Paris: Minuit, 1981.

GÉLY, R. La genèse du sentir: essai sur Merleau-Ponty. Bruxelles: Ousia, 2000.

HEIDEGGER, M. Sein und Zeit. 16. ed. Tübingen: Max Niemeyer Verlag, 1986.

HUSSERL, E. Ideen zu einer reinen Phänomenologie und phänomenologischen Philosophie. Den Haag: Martinus Nijhoff, 1976.

_. Idées (II) Idées directrices pour une phénoménologie et une philosophie phénoménologiques pures: Recherches phénoménologiques pour la constitution. Trad. E. Escoubas. Paris: PUF, 1982.

_. Formale und transzendentale Logik. Hamburg: Meiner, 1992. 
Expérience et jugement: recherches en vue d'une généalogie de la logique. Trad. D. Souche-Dagues. 3. ed. Paris: PUF, 2000.

—. Méditations cartésiennes: introduction à la phénoménologie. Trad. G. Peiffer et E. Lévinas. 9. ed. Paris: Vrin, 2001.

_. A crise das ciências europeias e a fenomenologia transcendental: uma introdução à filosofia fenomenológica. Trad. Diogo Falcão Ferrer. Lisboa: Centro de Filosofia Universitas Olisiponensis, 2008.

MERLEAU-PONTY, M. Phénoménologie de la perception. Paris: Gallimard, 1945.

"Discussion". In: Husserl: Cahiers de Royaumont. Paris: Minuit, 1959, p. 157-159.

_. Signes. Paris: Gallimard, 1960.

—. Le visible et l'invisible. Paris: Gallimard, 1964.

_. Les aventures de la dialectique. Paris: Gallimard, 1967.

_. La prose du monde. Paris: Gallimard, 1969.

—. L'eil et l'esprit. Paris: Gallimard, 1985.

_. La nature. Paris: Seuil, 1995.

_. Manuscrits inédits. Paris: Bibliothèque Nationale de France, 1992. "Husserl aux limites de la phénoménologie". In: Notes de cours sur L'origine de la géométrie de Husserl, suivi de Recherches sur la phénoménologie de Merleau-Ponty. Paris: PUF, 1998.

—. Parcours deux (1951-1961). Lagrasse: Verdier, 2000.

_. L'institution/La passivité: notes de cours au Collége de France (1954-1955). Paris: Belin, 2003.

MOURA, C. A. R. "A ciência e a 'reflexão radical"'. In: Manuscrito. UNICAMP vol. $1, \mathrm{n}^{\circ} 2$ (out./77), p. 119-142.

RICEUR, P. Á l'école de la phénoménologie. Paris: Vrin, 1986.

SCHELling, F. W. J. Essais. Trad. S. Jankélévitch. Paris: Aubier, 1946.

—. Les âges du monde. Trad. S. Jankélévitch. Paris: Aubier, 1949.

Ideias para uma filosofia da natureza. Trad. Carlos Morujão. Lisboa: Imprensa Nacional, 2001.

SILVA, C. A. F. A carnalidade da reflexão: ipseidade e alteridade em Merleau--Ponty. São Leopoldo, RS: Nova Harmonia, 2009.

_. A natureza primordial: Merleau-Ponty e o logos do mundo estético. Cascavel, PR: Edunioeste, 2010 (Série Estudos Filosóficos, n 12).

ZIELINSKI, A. Lecture de Merleau-Ponty et Levinas: le corps, le monde, l'autre. Paris: PUF, 2002. 